\title{
A Review on Biodegradable and Bioabsorbable Stents for Coronary Artery Disease
}

\author{
Prathibha Ramadugu ${ }^{1 *}$, Kanaka Latha Alikatte ${ }^{2}$ and Narendar Dhudipala ${ }^{3}$
}

${ }^{1}$ Kakatiya Institute of Pharmaceutical Sciences, Pembarthi, Warangal, India

${ }^{2}$ St. Peter's Institute of Pharmaceutical Sciences, Warangal, India

${ }^{3}$ University College of Pharmaceutical Sciences, Warangal, India

\begin{abstract}
In the recent years Angioplasty has made a significant progress and is being widely used in the treatment of atherosclerotic vascular disease. Drug-eluting stents are not only effective but are also raising the concerns associated like restenosis. Biodegradable stents are being developed as an alternative to permanent stents which may be a potential alternative in solving the problem of in-stent restenosis. When compared to metallic stents with a thin coated drug, a fully degradable stent may be more potential in targeted drug delivery. Biodegradable materials like polycarbonates, polyesters, corrodible metals and bacterial-derived polymers have been investigated by various research groups in designing stents. A biodegradable stent is considered to be perfect if it could be reliably deploy under the fluoroscopic guidance and locate the target lesion with an insignificant endovascular trauma. In addition the byproducts developed during the degradation should be nontoxic, lead to the minimal inflammation at the target site and should disappear in a minimal period of time without a noteworthy displacement from the deployment site. Even though stents made of biodegradable materials were launched into the market with initial clinical data, more advanced research is necessary to solve the various issues associated with these stents.
\end{abstract}

Keywords: Stents; Biodegradable; Bioabsorbable; Restenosis; Angioplasty

\section{Introduction}

Coronary artery disease (CAD) is one of the prominent causes of demise in the world. Despite large number of study reports on pathogenesis of atherosclerosis and the development of ischemic heart disease there are numerous questions that are unrequited. About $70 \%$ of the risk factors associated with the CAD events are addressed by the classic factors while the other $30 \%$ of the CAD events do not elucidate any relationship with the existing classical factors. In addition, it is still not clear why some signs are established while others are susceptible to falling-out and in turn leading to acute coronary syndromes $[1,2]$.

Percutaneous transluminal coronary angioplasty (PTCA) is one of the mechanical interventions which are used for the treatment of CAD [3]. Restenosis "the arterial healing response after injury incurred during revascularization" is a result of the local vascular expression of the biologic response to the injury. Recoil of the arteries during the healing is the primary factor that is responsible for the restenosis postPTCA [4]. Stents provide mechanical scaffolding and eliminate the vessel recoil and restenosis. But continuing pressure exerted by the stunt against the vessel wall may lead to neointimal tissue proliferation, over the stent and in turn initiate the recurrence of luminal narrowing due to in-stent restenosis (ISR). Brachytherapy and drug eluting stunts were considered to be the potential treatment method for the treatment of ISR but were associated with risk of edge restenosis and late thrombosis $[5,6]$. As the role of stents is temporary only till healing, reendothelialization and no benefits are found thereafter researchers have targeted the biodegradable and corrodible products used in medicine to develop biodegradable and bioabsorbable stents $[7,8]$.

In addition to the stents based on the advances developed by the scientific community other treatments like use of nitric oxide, carbon monoxide, oligonucleotides (Antisense) in the treatment of CAD and preventing restenosis have also been advanced. In the current review we summarized the different biodegradable, bioabsorbable stents that need for mechanical support and also explained about the other advances that are used in addition to or as an alternative to stents in the treatment of CAD and prevent the potential risks of restenosis.

\section{Biodegradable and Bioabsorbable Stents}

Despite the fact that stents are major breakthrough in the treatment of obstructive coronary artery disease, the device will remain as permanent implant/foreign body inside the artery after their intended use. There exists several questions till date; why should a device implanted just to prevent acute or sub-acute recoil occurring mainly after the initial days of procedure, and to deliver anti-proliferative dugs to prevent cell proliferation which is observed after 2-3 weeks of intervention, for life time? Issues with long term stay of stents in the artery include but not limited to, late restenosis, mechanical blockages, late development of malposition, etc. which made researchers to develop Biodegradable and Bioabsorbable stents.

Bio-degradable polymer based stents (BDS) have several advantages over permanent metallic stents [9]. Optimized polymer composition may facilitate more targeted drug delivery, limiting smooth muscle cell proliferation on the abluminal side, while simultaneously encouraging endothelialization on the luminal side $[10,11]$. Moreover, stents made of complete polymer may have a higher drug loading capacity. The magnetic resonance imaging/CT compatibility of BDS may result in more diagnostic interpretation since there is no interaction from

*Corresponding author: Prathibha Ramadugu, Kakatiya Institute of Pharmaceutical Sciences, Pembarthi, Warangal, India, Tel: 040-27626194; Fax: 040-27666347; E-mail: ramaduguprathibha@gmail.com

Received December 28, 2015; Accepted January 04, 2016; Published January 11,2016

Citation: Ramadugu P, Alikatte KL, Dhudipala N (2016) A Review on Biodegradable and Bioabsorbable Stents for Coronary Artery Disease. J Bioequiv Availab 8: 064067. doi: $10.4172 / \mathrm{jbb} .1000269$

Copyright: (c) 2016 Ramadugu P, et al. This is an open-access article distributed under the terms of the Creative Commons Attribution License, which permits unrestricted use, distribution, and reproduction in any medium, provided the original author and source are credited. 
Citation: Ramadugu P, Alikatte KL, Dhudipala N (2016) A Review on Biodegradable and Bioabsorbable Stents for Coronary Artery Disease. J Bioequiv Availab 8: 064-067. doi:10.4172/jbb.1000269

metallic stents. In addition, the avoidance of metallic stents may allow repeated percutaneous revascularization or surgical intervention if required [12].

There are several conditions to consider when selecting a polymer for the BDS [13]. These include, but not limited to, biocompatibility of the polymer, the strength of the polymer to avoid immediate recoil and lack of toxicity. Questions in regards to radial strength loss were of concern as there may be increased risk of stent fracture and migration over a period of time [14-17]. Furthermore, the long term biocompatibility of the breakdown products was relatively unknown [18]. Poly L-lactic acid (PLLA), polyglycolic acid (PGA), polycaprolactone (PCL) and poly (D, L-lactide/glycolide) copolymer (PDLA) are some of the suggested polymers for fabricating bioabsorbable stents. Each of these polymers was designed as either self-expanding or balloon expandable stents. Another proposed design is the hybrid stent, which combines polymeric absorbable stents with a metallic backbone to enable strength and prevent recoil [19-24].

Stack and colleagues at Duke University, Durham, NC, developed the first fully fabricated BDS, made of knitted poly-L-lactic acid (PLLA) [21]. This prototype stent could withstand up to $1000 \mathrm{~mm} \mathrm{Hg}$ of crush pressure, kept its radial strength for 1 month and was almost completely degraded by 9 months [25]. Igaki and Tamai further refined the design to PLLA monofilaments (molecular weight, $183 \mathrm{kDa}$ ) in a zigzag helical coil configuration (Figure 1) [26]. This arrangement was associated with reduced vascular injury at the implantation site, which led to a reduction in initial thrombus deposition and neointimal proliferation [26]. PLLA with low molecular mass, was associated with an intense inflammatory reaction, whereas a minimal inflammatory reaction was observed with molecular mass $>300 \mathrm{kDa}$ [27].

Several clinical studies were performed on humans to assess the safety of Igaki-Tamai stent made of biodegradable polymer PLLA [28-34]. Initially, Igaki and co-workers have evaluated the safety and efficacy of PLLA stent implanted in 15 patients. The results from the study conclude that, the percent diameter stenosis decreased from $64 \%$ before stenting to $12 \%$ after stenting and the study also confirmed the PLLA stents might not be associated with intimal hyperplasia than stainless steel stents $[30,35]$. In another study, Tsugi et al. reported a 1 year follow-up study of 50 patients who underwent stent implantation successfully in 63 lesions. Restenosis rates were $21 \%$ at 6 months and $19 \%$ at 12 months. Overall, these findings suggest us that the use of PLLA stents is safe with acceptable efficacy in human coronaries [31].

The bioabsorbable vascular solutions (BVS) everolimus-eluting stent from Abbott Vascular, Santa Clara, CA utilized highly crystalline poly lactic acid (PLA) as backbone material, which allows the stent to achieve the radial strength of MULTI-LINK VISION" metal stent. The surface of the stent is coated with 1:1 mixture of drug to amorphous PLA matrix, allowing $80 \%$ of the drug to be released in first 30 days (Figure 2). Results from the studies concluded that, the stent is bioabsorbed in $\sim 18$ months [36].

Another biodegradable polymer tyrosine poly (desaminotyrosyltyrosine ethyl ester) carbonate was utilized to make REVA stent by Reva Medical, with polycarbonate backbone. The REVA stent has a unique slide and locking design that provides both flexibility and strength (Figure 3 ). This design with polycarbonate backbone imparts high tensile strength and apparently negligible recoil with balloon deployment. From the human clinical trials it suggested that there is no recoil observed at the end of 6 months [37-41].

The IDEAL ${ }^{\mathrm{TM}}$ biodegradable stent from Bioabsorbable Therapeutics
Inc. was made from Poly-anhydride ester (PAE) with sirolimus and salicylic acid incorporated, to provide both anti-inflammatory and anti-proliferative property (Figure 4). Initial human clinical study demonstrated the structural integrity with no evidence of recoil. But, the stents failed to show the anti-proliferative property which could be due to lesser drug load. Therefore, second generation IDEAL ${ }^{\mathrm{TM}}$ stents with higher drug load and slower drug release were under investigation [42].

Another interesting concept is the multi-layered biodegradable stent designed by Eury et al. which is made of various polymers such as PLLA, PGA, PCL, poly-orthoesters or poly-anhydrides [43]. The unique feature of this stent is that 1 layer addresses the structural requirements of the stent and an additional layer controls the drug release.

\section{Limitation of Biodegradable Stents}

Despite the clinical advantages associated with biodegradable polymer stents, there exist several limitations. The polymer stents are associated with significant degree of local inflammation. These stents are not as strong as metal stents, which may result in recoil and may

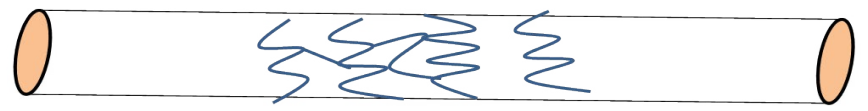

Figure 1: Igaki-Tamai stent made of biodegradable polymer PLLA with zigzag helical coil design and has been used for local delivery of transilast and paclitaxel.

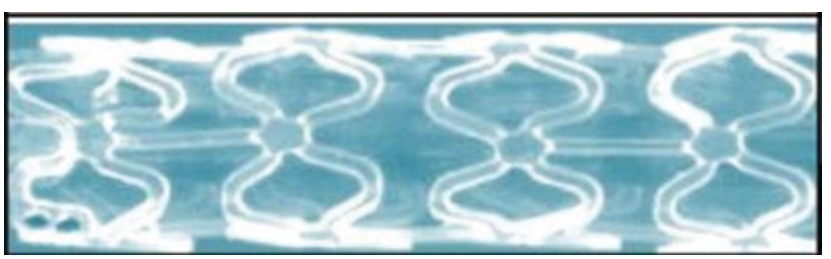

Figure 2: Abbott vascular BVS stent made of biodegradable polymer PLA

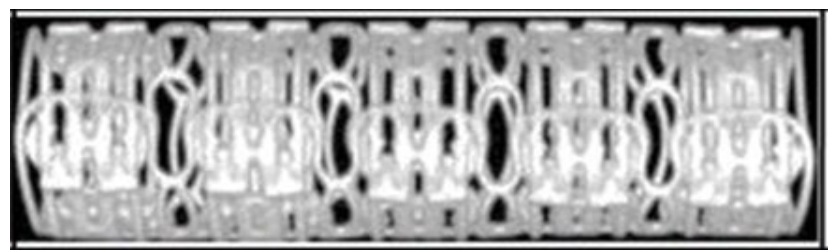

Figure 3: The REVA stent made from monomeric units of amino L-Tyrosine poly (desaminotyrosyl-tyrosine ethyl ester) carbonate and has been used for delivery of paclitaxel.

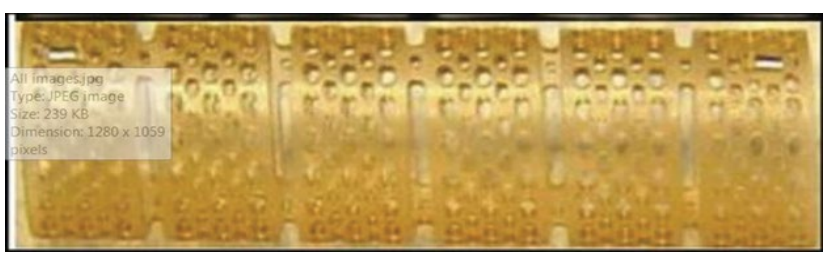

Figure 4: The IDEAL ${ }^{\mathrm{TM}}$ stent from bioabsorbable therapeutics made of biodegradable polymer pae and is used to deliver salicylic acid and sirolimus. 
require strong backbone, especially in small vessels. These polymer stents may require special storage conditions and have a shorter shelf life [7].

\section{Bioabsorbable Stents}

Metal bioabsorbable stents are becoming attractive since they have the potential to overcome the limitations of biodegradable polymer based stents and to perform similarly to stainless steel metal stents. So far, only two classes of materials have been proposed and studied in humans include magnesium $(\mathrm{Mg})$ and Iron $(\mathrm{Fe})$. Use of both $\mathrm{Mg}$ and Fe metals as bioabsorbable stents can be justified by the well-known human metabolism. The systemic toxicity of $\mathrm{Mg}$ and $\mathrm{Fe}$ was very well documented. Therefore, bioabsorbable stents have gain more interest than the polymer stents [44-51].

Several Mg alloys have been investigated so far by several research groups. $\mathrm{Mg}$ alloys have very limited ductility compared with most $\mathrm{Fe}$ alloys. Advance processing techniques may improve the ductility of $\mathrm{Mg}$ alloys, for e.g. Hot Melt Extrusion of Mg-Ca showed better strength and ductility [52]. Several clinical investigations have been studied using $\mathrm{Mg}$ alloys as bioabsorbable metal stent. Heublein and co-workers have tested $\mathrm{Mg}$ alloy (AE 21) in porcine coronary arteries [53]. From the studies, they observed that, there was over stretch injury in the arteries because of assymetrical expansion of stent and strut positioned within adventia caused inflammation and exaggerated intimal hyperplasia. But, the natural process of arterial growth was not disturbed in young pigs and the in-stent area increased from $3.28 \mathrm{~mm}^{2}$ at 35 days to 6.15 $\mathrm{mm}^{2}$ at 56 days.

Another most promising and most studied bioabsorbable metal stent is Fe. However, pure Fe unlike most other metals its shows ferromagnetic property, which may interfere with magnetic resonance imaging observation. Therefore, this property was altered by alloying with manganese $(\mathrm{Mn})$ which resulted in anti-ferromagnetic property, while improving its mechanical properties [50]. Since the in vivo degradation of the Fe stent is slow, the cytotoxic property of Fe was found to be insignificant [49]. Relatively small amount of $\mathrm{Fe}(\sim 40 \mathrm{mg})$ was found in stent when compared to systemic availability $(447 \mathrm{mg} / \mathrm{L})$ makes it least toxic systemically. Peuster and co-workers have studied and reported the experimental studies of bioabsorbable Fe stent $(\sim$ $41 \mathrm{mg}$ ) into the aorta of New Zealand white rabbits (Figure 5). The results showed there was no adverse side effects resulted during the study period. Moreover, there was neither pronounced neointimal proliferation nor significant inflammatory response.

The important clinical application for bioabsorbable metal stent (AMS) is for pediatric use. Schranz et al. [54] first reported the use of AMS for acute treatment of a new-born baby with severly impaired

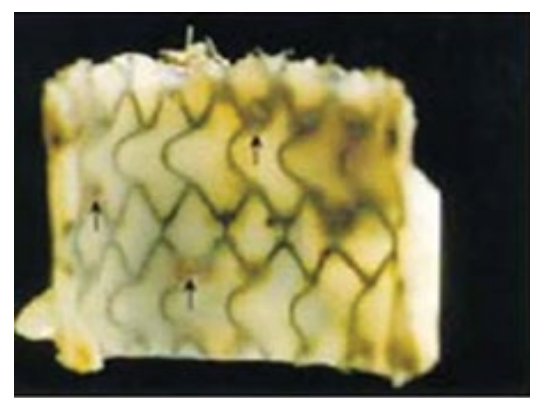

Figure 5: Rabbit aorta showing the iron stent 12 months after implantation. heart function. A recent study revealed early restenosis following AMS implantation in 2 months old girl. This study demands the further improvements in the field of Mg alloys stent technology [55]. PROGRESS-AMS (Clinical Performance and Angiographic Results of Coronary Stent) study was the first human coronary clinical trials reported. The study showed the AMS stents can be safely delivered and expanded at high pressure in simple coronary artery lesions with good mechanical scaffolding similar to that obtained from BMS. In conclusion from several clinical studies, implantation of AMS-1 is safe in human coronary and peripheral arteries and is associated with high procedural success rate. Degradation rate of the metal stents was as expected without any adverse events. But, however implantation was associated with higher restenosis rate than expected [54-57].

\section{Conclusion}

With increasing trends in the people affected by coronary heart diseases and the advances in technology the treatments for CRD using intervention techniques will increase. Intervention treatments may also be followed by the physicians for patients with multi-vessel disease, diabetes, etc. Despite the advantages from intervention therapies there are also limitations like restenosis which can be solved by using different non interventional therapies. More research advances addressing the limitations associated with the existing therapies will further benefit the population that is affected by CRD.

\section{References}

1. Thygesen K, Alpert JS, Jaffe AS, Simoons ML, Chaitman BR, et al. (2012) Third universal definition of myocardial infarction. J Am Coll Cardiol 60: 1581-1598.

2. Perk J, De Backer G, Gohlke H, Graham I, Reiner Z, et al. (2012) European Guidelines on cardiovascular disease prevention in clinical practice (version 2012). The Fifth Joint Task Force of the European Society of Cardiology and Other Societies on Cardiovascular Disease Prevention in Clinical Practice (constituted by representatives of nine societies and by invited experts). Eur Heart J 33: 1635-1701.

3. Landau C, Lange RA, Hillis LD (1994) Percutaneous transluminal coronary angioplasty. N Engl J Med 330: 981-993.

4. Mintz GS, Popma JJ, Pichard AD, Kent KM, Satler LF, et al. (1996) Arterial remodeling after coronary angioplasty: a serial intravascular ultrasound study. Circulation 94: 35-43.

5. Condado JA, Waksman R, Gurdiel O, Espinosa R, Gonzalez J, et al. (1997) Long-term angiographic and clinical outcome after percutaneous transluminal coronary angioplasty and intracoronary radiation therapy in humans. Circulation 96: 727-732

6. Teirstein PS, Massullo V, Jani S, Popma JJ, Mintz GS, et al. (1997) Catheterbased radiotherapy to inhibit restenosis after coronary stenting. N Engl J Med 336: 1697-1703.

7. Waksman R, Pakala R (2010) Biodegradable and bioabsorbable stents. Curr Pharm Des 16: 4041-4051.

8. Ormiston JA, Serruys PW (2009) Bioabsorbable coronary stents. Circ Cardiovasc Interv 2: 255-260.

9. Erne P, Schier M, Resink TJ (2006) The road to bioabsorbable stents: reaching clinical reality? Cardiovasc Intervent Radiol 29: 11-16.

10. Ramcharitar S, Vaina S, Serruys PW (2007) The next generation of drugeluting stents: what's on the horizon? Am J Cardiovasc Drugs 7: 81-93.

11. Loria MJ, White SW, Robbins SA, Salmeto AL, Hymel KA, et al. (2013) Brainderived neurotrophic factor response in vulnerable and resilient genetic lines in the chick anxiety-depression model. Behav Brain Res 245: 29-33.

12. Aoki J, Ong AT, Rodriguez Granillo GA, McFadden EP, van Mieghem CA, et al. (2005) "Full metal jacket" (stented length $>$ or $=64 \mathrm{~mm}$ ) using drug-eluting stents for de novo coronary artery lesions. Am Heart J 150: 994-999.

13. Byrne RA, Kastrati A, Massberg S, Wieczorek A, Laugwitz KL, et al. (2011) Biodegradable polymer versus permanent polymer drug-eluting stents and 
Citation: Ramadugu P, Alikatte KL, Dhudipala N (2016) A Review on Biodegradable and Bioabsorbable Stents for Coronary Artery Disease. J Bioequiv Availab 8: 064-067. doi:10.4172/jbb.1000269

everolimus-versus sirolimus-eluting stents in patients with coronary artery disease: 3-year outcomes from a randomized clinical trial. J Am Coll Cardiol 58: $1325-1331$

14. Venkatraman S, Poh TL, Vinalia T, Mak KH, Boey F (2003) Collapse pressures of biodegradable stents. Biomaterials 24: 2105-2111.

15. Uurto I, Juuti H, Parkkinen J, KellomÃaki M, Keski-Nisula L, et al. (2004) Biodegradable self-expanding poly-L/D-lactic acid vascular stent: a pilot study in canine and porcine iliac arteries. J Endovasc Ther 11: 712-718.

16. Juluri A, Peddikotla P, Repka MA, Murthy SN (2013) Transdermal iontophoretic delivery of propofol: a general anaesthetic in the form of its phosphate salt. $J$ Pharm Sci 102: 500-507

17. 17. Köllmer M, Popescu C, Manda P, Zhou L, Gemeinhart RA (2013) Stability of benzocaine formulated in commercial oral disintegrating tablet platforms. AAPS PharmSciTech 14: 1333-1340.

18. Vogt F, Stein A, Rettemeier G, Krott N, Hoffmann R, et al. (2004) Long-term assessment of a novel biodegradable paclitaxel-eluting coronary polylactide stent. Eur Heart J 25: 1330-1340.

19. Hastings GW (2012) Cardiovascular biomaterials. Springer Science and Business Media.

20. Murphy JG, Schwartz RS, Huber KC, Holmes DR Jr (1991) Polymeric stents: modern alchemy or the future? J Invasive Cardiol 3: 144-148.

21. Stack RS, Califf RM, Phillips HR, Pryor DB, Quigley PJ, et al. (1988) Interventional cardiac catheterization at Duke Medical Center. Am J Cardiol 62: 3F-24F.

22. Xu X, Al-Ghabeish M, Rahman Z, Krishnaiah YS, Yerlikaya F, et al. (2015) Formulation and process factors influencing product quality and in vitro performance of ophthalmic ointments. Int J Pharm 493: 412-425.

23. Juluri A, Modepalli N, Jo S, Repka MA, Shivakumar HN, et al. (2013) Minimally invasive transdermal delivery of iron-dextran. J Pharm Sci 102: 987-993.

24. Juluri A, Vanaja K, Murthy SN (2014) Passive delivery techniques for transcutaneous immunization. Journal of Drug Delivery Science and Technology 24: 271-276.

25. van der Giessen WJ, Lincoff AM, Schwartz RS, van Beusekom HM, Serruys PW, et al. (1996) Marked inflammatory sequelae to implantation of biodegradable and non-biodegradable polymers in porcine coronary arteries. Circulation 94: 1690-1697.

26. Tsuji T, Tamai H, Kyo E (1998) The effect of PLLA stent design on neointimal hyperplasia. J Cardiol 32: 235A

27. Lincoff AM, Furst JG, Ellis SG, Tuch RJ, Topol EJ (1997) Sustained local delivery of dexamethasone by a novel intravascular eluting stent to prevent restenosis in the porcine coronary injury model. J Am Coll Cardiol 29: 808-816.

28. Kumar V (2009) Future outlook for drug eluting stents. Drug-Device Combination Products: Delivery Technologies and Applications, LA (Eds), UK: Woodhead Publishing Limited: 117.

29. Serruys PW, Ormiston JA, Onuma Y, Regar E, Gonzalo N, et al. (2009) A bioabsorbable everolimus-eluting coronary stent system (ABSORB): 2-year outcomes and results from multiple imaging methods. Lancet 373: 897-910.

30. Tamai H, Igaki K, Kyo E, Kosuga K, Kawashima A, et al. (2000) Initial and 6-month results of biodegradable poly-I-lactic acid coronary stents in humans. Circulation 102: 399-404

31. Tamai H (2004) Biodegradable stents four year follow-up. Presentation at TCT

32. Manda P, Sammeta SM, Repka MA, Murthy SN (2012) lontophoresis across the proximal nail fold to target drugs to the nail matrix. J Pharm Sci 101: 23922397.

33. Yang Y, Manda P, Pavurala N, Khan MA, Krishnaiah YS (2015) Development and validation of in vitro-in vivo correlation (IVIVC) for estradiol transdermal drug delivery systems. J Control Release 210: 58-66.

34. Juluri A, Popescu C, Zhou L, Murthy RN, Gowda VK, et al. (2015) Taste Masking of Griseofulvin and Caffeine Anhydrous Using Kleptose Linecaps DE17 by Hot Melt Extrusion. AAPS PharmSciTech

35. Popescu C, Manda P, Juluri A, Janga KY, Cidda M, et al. (2015) Enhanced Dissolution Efficiency of Zaleplon Solid Dispersions via Modified ß-Cyclodextrin Molecular Inclusion Complexes. J. Pharm Pharm Scien 1: 12-21.
36. Ormiston JA, Serruys PW, Regar E, Dudek D, Thuesen L, et al. (2008) A bioabsorbable everolimus-eluting coronary stent system for patients with single de-novo coronary artery lesions (ABSORB): a prospective open-label trial. Lancet 371: 899-907.

37. Schultz R (2006) REVA medical inc. Bioresorbable technology. Cardiovascular Research Technologies Annual Meeting 19: 414-421.

38. Grube E (2009) Bioabsorbable stent. The Boston scientific and REVA technology. EuroPCR: 19-22.

39. Garg S, Serruys P (2009) Biodegradable stents and non-biodegradable stents. Minerva Cardioangiol 57: 537-565.

40. Manda P, Hargett JK, Vaka SR, Repka MA, Murthy SN (2011) Delivery of cefotaxime to the brain via intranasal administration. Drug Dev Ind Pharm 37 1306-1310.

41. Juluri A, Narasimha Murthy S (2014) Transdermal iontophoretic delivery of a liquid lipophilic drug by complexation with an anionic cyclodextrin. J Control Release 189: 11-18.

42. Jabara R (2009) Poly-anhydride based on salicylic acid and adipic acid anhydride. Barcelona, Spain: EuroPCR.

43. Eury K (1994) Multi-layered biodegradable stent and method for its manufacture. European Patent 604022: A1.

44. Heublein B, Rohde R, Kaese V, Niemeyer M, Hartung W, et al. (2003) Biocorrosion of magnesium alloys: a new principle in cardiovascular implant technology? Heart 89: 651-656

45. Peeters P, Bosiers M, Verbist J, Deloose K, Heublein B (2005) Preliminary results after application of absorbable metal stents in patients with critical limb ischemia. J Endovasc Ther 12: 1-5.

46. Waksman R, Pakala R, Kuchulakanti PK, Baffour R, Hellinga D, et al. (2006) Safety and efficacy of bioabsorbable magnesium alloy stents in porcine coronary arteries. Catheter Cardiovasc Interv 68: 607-617.

47. Peuster M, Wohlsein P, Brugmann M, Ehlerding M, Seidler K, et al. (2001) A novel approach to temporary stenting: degradable cardiovascular stents produced from corrodible metal-results $6-18$ months after implantation into New Zealand white rabbits. Heart 86: 563-569.

48. Waksman R, Pakala R, Baffour R, Seabron R, Hellinga D, et al. (2008) Short term effects of biocorrodible iron stents in porcine coronary arteries. J Interv Cardiol 21: 15-20.

49. Peuster M, Hesse C, Schloo T, Fink C, Beerbaum P, et al. (2006) Long-term biocompatibility of a corrodible peripheral iron stent in the porcine descending aorta. Biomaterials 27: 4955-4962.

50. Hermawan H, Alamdari H, Mantovani D, Dubé D (2008) Iron-manganese: new class of metallic degradable biomaterials prepared by powder metallurgy. Powder Metallurgy 51: 38-45.

51. Manda P, Angamuthu M, Hiremath SR, Raman V, Murthy SN (2014) lontophoretic drug delivery for the treatment of scars. J Pharm Sci 103: 16381642.

52. Li Z, Gu X, Lou S, Zheng Y (2008) The development of binary Mg-Ca alloys for use as biodegradable materials within bone. Biomaterials 29: 1329-1344.

53. Heublein B, Hausdorf G (2002) Metallic stent which is degradable in vivo. EPO

54. Schranz D, Zartner P, Michel-Behnke I, Akintürk H (2006) Bioabsorbable metal stents for percutaneous treatment of critical recoarctation of the aorta in a newborn. Catheter Cardiovasc Interv 67: 671-673.

55. McMahon CJ, Oslizlok P, Walsh KP (2007) Early restenosis following biodegradable stent implantation in an aortopulmonary collateral of a patient with pulmonary atresia and hypoplastic pulmonary arteries. Catheter Cardiovasc Interven 69: 735-738

56. Zartner P, Cesnjevar R, Singer H, Weyand M (2005) First successfu implantation of a biodegradable metal stent into the left pulmonary artery of a preterm baby. Catheter Cardiovasc Interv 66: 590-594.

57. Zartner P, Buettner M, Singer H, Sigler M (2007) First biodegradable meta stent in a child with congenital heart disease: evaluation of macro and histopathology. Catheter Cardiovasc Interven 69: 443-446. 